East African Medical Journal Vol. 87 No. 5 May 2010

EVALUATION AND HISTOLOGICAL MATURATION CHARACTERISTICS OF FIBROUS DYSPLASIA AND OSSIFYING FIBROMA : A CASE SERIES

J. L. Moshy, DDS, MDS- OMS, Lecturer, Department of Oral Surgery and Oral Pathology, H. A. Mwakyoma, MD, MSc, MMed, Senior Lecturer, Department of Histopathology and Morbid Anatomy, Muhimbili University of Health and Allied Sciencies, P. O. Box 65014, Dar es Salaam, Tanzania and M.L. Chindia, BDS, MSc, FFDRCSI, Associate Professor, Department of Oral and Maxillofacial Surgery, Oral Medicine and Oral Pathology, School of Dental Sciences, University of Nairobi, P.O. Box 19676 - 00202, Nairobi, Kenya

Request for reprints to: Dr. J. L. Moshy, Department of Oral Surgery and Oral Pathology, Muhimbili University of Health and Allied Sciences, P.O. Box 65014, Dar es Salaam, Tanzania

\title{
EVALUATION AND HISTOLOGICAL MATURATION CHARACTERISTICS OF FIBROUS DYSPLASIA AND OSSIFYING FIBROMA: A CASE SERIES
}

\author{
J. L. MOSHY, H. A. MWAKYOMA and M. L. CHINDIA
}

\begin{abstract}
Background:Fibrous dysplasia (FD) and ossifying fibroma (OF) are benign fibro-osseous lesions (FOLS) that are generally considered to be separate entities distinguishable by histologic and radiographic features. The histological maturation of these lesions involves an initial fibrous state, an intermediate mixed and a final mineralised stage.

Objective: To correlate the mineralisation of OF and FD with the duration of the lesion.

Design: A retrospective histopathological analysis of archival material including sixteen cases documented over a three-year period was performed to distinguish FD from OF.

Setting: The relevant data of FOLs diagnosed as OF and FD were retrieved from the archival records of the Departments of Oral Surgery/Oral Pathology and Histopathology/ Morbid Anatomy, Muhimbili University of Health and Allied Sciences.

Results: Remarkably, in this series, none of the FD and OF lesions occurred in patients aged below 10 or over 50 years. The histopathological comparison of the various nonmineralised components in both the lesions in relation to lesion age-maturity was not statistically significant $(P>0.05)$.

Conclusion: The histopathological ratio of the mineralised to non-mineralised components may not be directly indicative of the maturity of both OF and FD.
\end{abstract}

\section{INTRODUCTION}

Tumours or other lesions with various types of mineralisation are encountered frequently in the maxillo facial region. In the maxillo-facial region. These mineralised tissues have been described as osseous-cementum tissues or other kinds on the basis of histopathological findings (1). Fibro-osseous lesions (FOLs) represent a variety of mineralised proliferations characterised by different morphologic patterns of osseous, cemental and / or ovoid-curvoid mineralised deposits (2). Fibrous dysplasia (FD) and ossifying fibroma (OF) belong to this group of FOLs. They are clinically recognised entities that are not easily differentiated histopathologically because of the lack of specific microscopic features (3). Most authors consider FD and OF to be histologically similar, the sole differentiating feature being a fibrous capsule surrounding OF lesions and infrequently observed in those of FD (4). Other authors indicate that $\mathrm{OF}$ is characterised by an abundant presence of osteoblasts and osteoclasts; and that on comparing both disorders the trabecular distribution is seen to be more regular in FD with few collagen and vascular elements and increased cellularity (5). The composition of specific features of these lesions may vary in individual cases depending on differentstages of the lesion.

On the other hand, the radiological appearance of these lesions depends upon their maturity (5). Scuibba and Younai (6) reported a higher proportion of radiolucent lesions with the youngest mean age and lowest proportion in the oldest mean age. Furthermore, the appearance of complete 
radiolucence only in younger cases suggests that mineralisation will occur increasingly with maturity. In the present study, we aimed at investigating whether the mineralisation that takes place in FD and OF may be related to the duration of the lesions.

\section{MATERIALS AND METHODS}

Study design: A retrospective demographic and histopathological analysis was performed of sixteen cases of archival FD and OF records and material documented over a three year period between March 2003 and 2006.

Study setting: This investigation was carried out at the Muhimbili National Hospital, Tanzania.

Method: Archival material including FOLs diagnosed as FD and OF was subjected to re-evaluation and analysis. Paraffin embedded tissue blocks for these lesions were retrieved from the archives and sectioned. Slides were stained according to the Haematoxylin and Eosin Technique for histopathological verification. All slides were then re-evaluated for confirmation of the diagnosis and for categorisation of the various histological components including those mineralised and the non-mineralised.

Study parameters: Slides of each case were analysed on the basis of selected histopathological parameters that consisted of the shape and arrangement of mineralised components: thick curvilinear trabeculae, metaplastic woven bone in a fibrous stroma, irregular cementoid masses, separate bony trabeculae, variable amounts of lamellar bone, bone trabeculae with large osteocytes within lacunae and osteoblastic rimming; cellularity and a pattern of non-mineralised components (storiform pattern, giant cells, free haemorrhage, dense and loose collagen).

Data were entered into acomputer software and statistical analysis performed using the pathologically mineralised and non-mineralised components; and the duration of each lesion was evaluated with the Chi-square test.

\section{RESULTS}

The distribution of the FD and OF lesions according to gender and age is presented in Table 1. Table 2 shows the pattern of mineralised components in relation to the duration of $\mathrm{OF}$ and FD lesions. Remarkably, in this series, none of these lesions occupied in patients aged below 10 or over 50 years. The histopathological comparison of the variousnonmineralised components in both the FD and OF lesions in relation to lesion age-maturity was not statistically significant $(p>0.05)$. Generally, the appearances of the non-mineralised and mineralised components at different lesion ages for FD are depicted in Figure 1 (at two years) and Figure 2 (at 10 years). Similarly for $\mathrm{OF}$, the component appearances are shown in Figure 3 (at two years) and Figure 4 (at three years). Apparently, there may be no relationship between the age maturity of these lesions and the natureratio of the histological components.

Table 1

Distribution of FD and OF lesions according to gender and age

\begin{tabular}{lccc}
\hline $\begin{array}{l}\text { Age group } \\
\text { (years) }\end{array}$ & Male & Female & Total \\
\hline $0-10$ & - & - & - \\
$11-20$ & 2 & 2 & 4 \\
$21-30$ & 1 & 5 & 6 \\
$31-40$ & 2 & 2 & 4 \\
$41-50$ & - & 2 & 2 \\
$50+$ & - & - & - \\
\hline Total & 5 & 11 & 16 \\
\hline
\end{tabular}




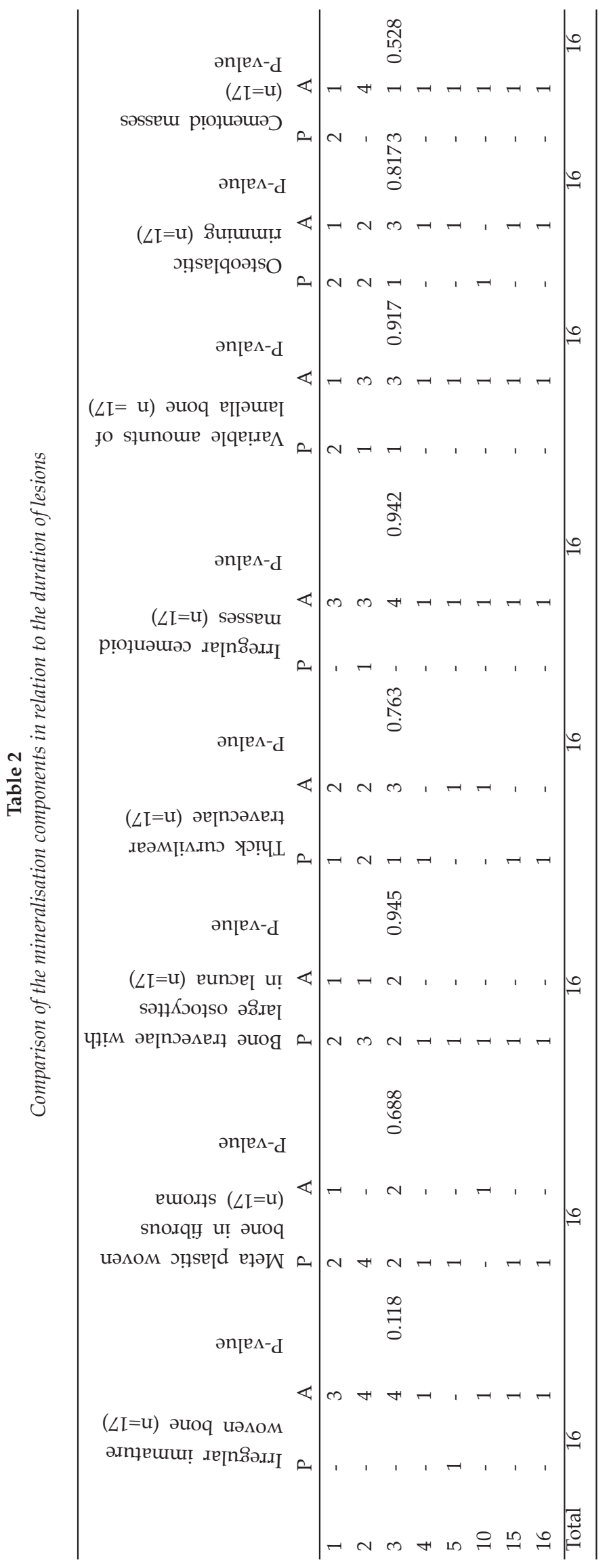


Figure 1

Appearance of an FD lesion diagnosed at three years of presentation (HE E. original magnification $x 40$ )

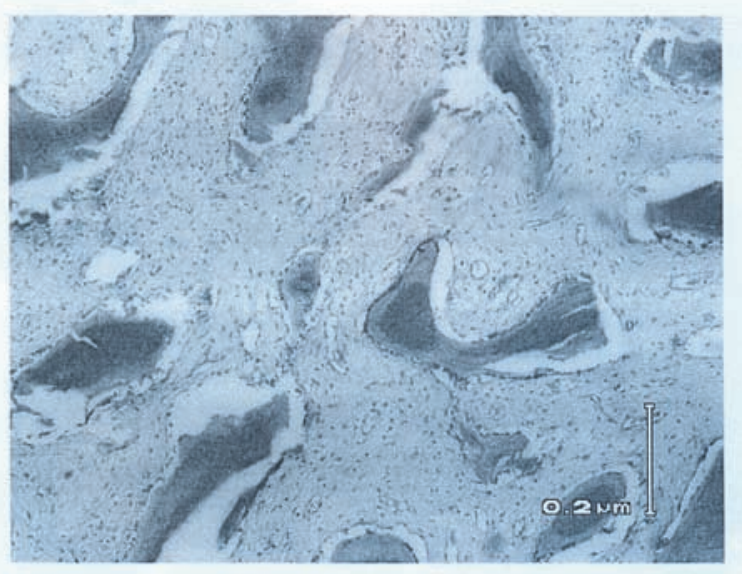

Figure 2

Appearance of an FD lesion diagnosed after 10 years of onset ( $H$ \& E. original magnification $x 40$ )

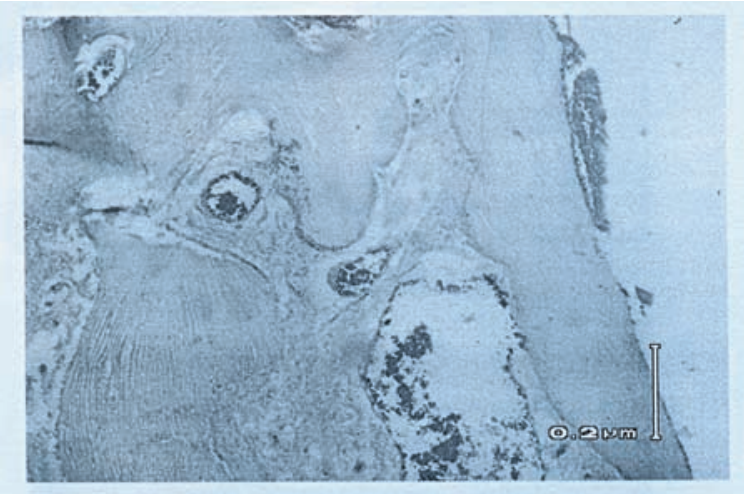

Figure 3

Appearance of OF presenting two years after onset $(H \mathcal{E}$ E. original magnification $x 40$ )

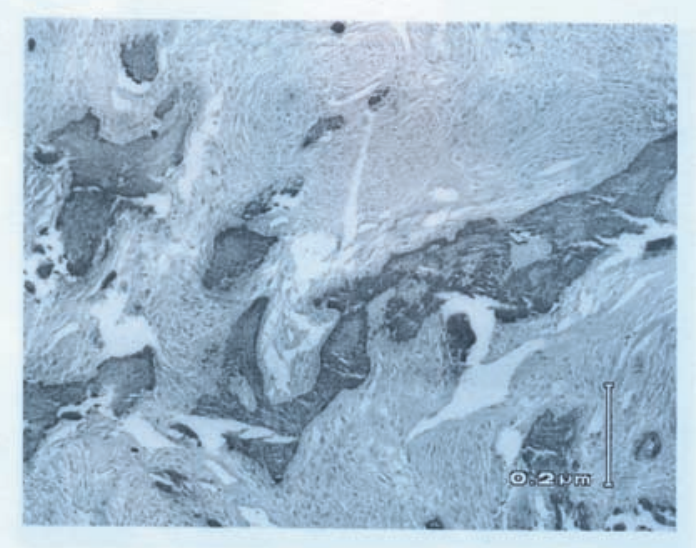

Figure 4

Appearance of OF diagnosed at a three year duration $(H$ $\mathcal{E}$ E. original magnification $x 40$ )

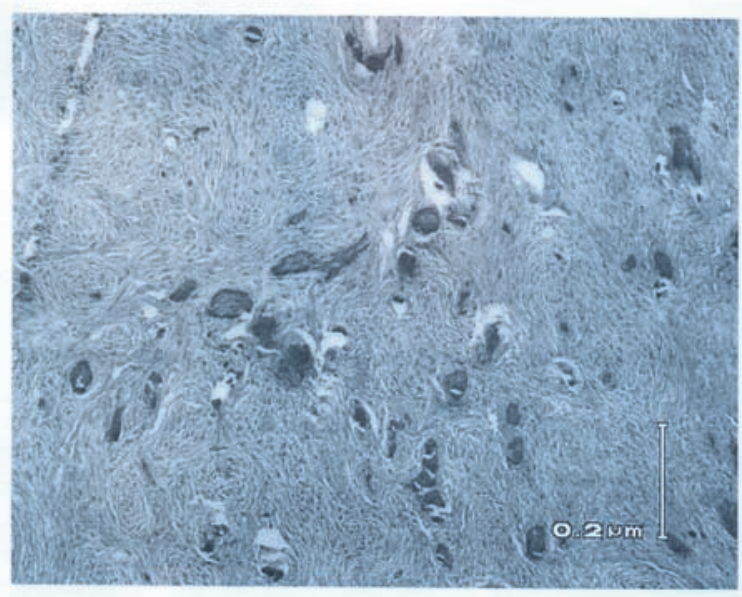

DISCUSSION

Fibro-osseous lesions of the jaws share similarities in radiographic and clinical appearance, histogenesis and histopathology; and consequently pose difficulty in diagnosis, classification and treatment (7). OF are benign FOLs that are generally considered to be separate entities, distinguished by histologic and radiographic features (8). Clinical analysis of the sixteen cases of FOLs diagnosed as FD and OF in the presentstudy revealed that females were more affected by both lesions and FD occurred more in the maxilla while OF had a preponderance for the mandible. The finding that females were more affected by the two lesions compared to males correlates well with previous studies $(1,2,4,10,16)$ reported in the literature. This observation may be due to the fact that female sex hormones or hormonal changes could be responsible for triggering the growth of these lesions. On the other hand, the reason for the differential distribution of the two lesions between the maxilla and mandible is not known. However, it has been proposed that inflammatory processes secondary to eitherinfections or trauma may cause the development of theselesions. Therefore, it is conceivable that different populations of cells may respond in a lineage-dependant manner to mechanical stress in terms of their amount of cyclicadenosine-monophosphate (CAMP) and insulin-like growth factor-l and hence could be the reason for the distribution. In addition, the anatomic and functional heterogeneity within individual bone units could also be the reason for this distribution. In the present study the peak age of occurrence of these lesions was in the 
third decade of life which is different from what other studies $(7,11-13,16)$ havereported. The differencemight be attributed to variations in methodology and the number of cases evaluated in these studies.

Shimazu et al. (1) reported that the crystallinity of apatite crystals in pathogenic FOL tissue exhibits an improvement with tissue maturation, approaching the level of crystallinity of the age-matched bone crystals. Zimmerman et al. (14) reported that serial roentgenograms in several cases of FD showed that some lesions became mineralised as the patient aged. The osseous or more mineralised tumours were found in older patients and the average duration of these lesions was greater. The present study suggests that the stage of mineralisation of these lesions (FD and $\mathrm{OF}$ ) may not be directly related to the age of the lesion in terms of mineralisation to the histological components (mineralised and non-mineralised) found within them. Reed (15) studied serial biopsies in three cases of FD which showed persistence of woven bone afterintervals of up to 10 years. It was believed that FD represented a permanent maturation arrest in the woven bone stage. MacDonald-Jankowski (16) reported that the variation in the density within radiographs of FD may indicate that different areas of the lesion mature at different times. However, Cooke (17) in another study did not observe radiographic changes in comparable films of FOLs over an interval of 10 years.

The present study and previous other investigations reflect the complexity of these lesions in terms of histologic and radiographicmaturation. Since the age of these lesions as reported in the present study may not directly affect mineralisation of histological components within them, it seems that, there could be certain regulatory mechanisms of mineralisation that are yet to be understood. The persistence of woven bone after intervals of 10 years as reported by Reed supports the assumption that once metaplastic change has taken place in these lesions to certain histological components, they could in fact persist for the whole period of the existence of the lesions. The metaplastic change seems to be controlled by cells which were oncogenic or developmental in nature but still express osteogenic phenotypes. Similarly as in the present study the mineralisation components within the analysed lesions may have been "biologically controlled" by cells and did not depend on the duration (age) or maturation of the conditions.

In conclusion, the histopathological ratio of the mineralised to non-mineralised components may not be directly indicative of the maturity of both OF and FD.

\section{ACKNOWLEDGEMENTS}

To the administrative organs of the Muhimbili University of Health and Allied Sciences and MuhimbiliNational Hospital, DaresSalaam, Tanzania for providing the material utilised for the study and the permission to present the findings for consideration to publish. Our sincere gratitude to Mary Mwangi at the Department of Oral and Maxillofacial Surgery, Oral Pathology and Oral Medicine, University of Nairobi for secretarial services

\section{REFERENCES}

1. Shimazu, Y., Hiratsuka, T., Sato, K., Yagishita, H. and Aoba, T. Tissue maturation of fibro-oseous lesions with respect to the inorganic constituents and crystallographic features. Oral Med. Oral.Pathol.1998; 3: 61-66.

2. Eversole, L.R., Leider, A.S. and Nelson, K. Ossifying fibroma: a clinicopathologic study of sixty-four cases. Oral. Surg. Oral. Med. Oral. Pathol. 1985; 60: 505-511.

3. Lan, Su., Dwight, R.W. and Waldron, C.A. Distinguishing features of focal cemento-osseous dysplasia and cemento-ossifying fibroma. I . Pathologic spectrum of 316 cases. Oral Surg. Oral Med. Oral Pathol. Oral Radiol. Endod. 1997; 84: 301- 309.

4. Zachariades, N., Vairaktaris, E., Papanicolaou, S., et al. Ossifying fibroma of the jaws. Review of the literature and report of 16 cases. Int. J. Oral. Surg. 1984; 13: 1- 6 .

5. McDonald -Jankowski, D.S. Cemento-ossifying fibromas in the jaws of Hong Kong Chinese. Dentomaxillofac. RAdoll. 1988; 27: 298-304.

6. Sciubba, J.J. and Younai, F. Ossifying fibroma of the mandible and maxilla. Review of 18 cases. J. Oral. Pathol. Med. 1989; 18: 315-321.

7. Antonelli, J.R. Ossifying fibroma of the maxillary sinus. A case report. Ann. Dent. 1989; 48: 33-36.

8. Voytek, T.M., Ro, J.Y., Edeiken, J. and Ayala, A.G. Fibrous dysplasia and cemento-ossfying fibroma. A histological spectrum. Am. J. Surg. Pathol. 1995; 7: 775- 781.

9. Lan, S.U., Dwight, R.W. and Waldron, C.A. Distinguishing features of focal cementoosseous dysplasis and cemento-ossifying fibromas n. Aclinical and radiographic spectrum of 316 cases. Oral Surg. Oral. Med. Oral Pathol. Endod. 1997; 84: 540-549.

10. Waldron, C. A. Fibro-osseous lesions of the jaws. J. Oral Maxillofac. Surg. 1985; 43: 249-262.

11. MacDonald-Jankowski, D.S. Fibro-osseus lesiosn of the face and jaws. Clin. Radiol. 2004; 59: 11-25.

12. Tasar, F., Giray, C.B., Tasman, U. and Saysel, M.Y. Ossfying fibroma. A case report. Turk. J. Padiatr. 1996; 38: 265-270.

13. Cuisia, Z.E., Brahnon RB. Peripheral ossifying fibroma. ASDC J. Dent. Child. 1996; 63: 135-138.

14. Zimmerman, D.C., Dahlin, D.C. and Stafne, E.C. Fibrous dysplasia of the maxilla and mandible. Oral Path. 1958; 11: 55 - 68.

15. Reed, R.J. Fibrous dysplasia of bone. Arch. Pathol. 1963; 75: 480.

16. MacDonald-Jankowski, D. Fibrous dysplasia in the jaws of Hong-Kong population: adiographic presentation and systemic review. Dent. Maxillofac. Radiol. 1999; 28: 195-202.

17. Cooke, B.E.D. Benign fibro-osseous enlargements of the jaws. Brit Dent. J. 1957; 103: 1-14 and 49-59. 